\title{
925 一輪車ロボットの制御に関する研究
}

\section{The Control Analysis of Unicycle Robot}

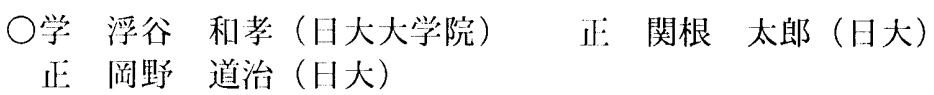

Kazutaka UKIYA, Nihon University, Kandasurugadai 1-8-14, Chiyoda-ku, Tokyo

Taro SEKINE, Nihon University

Michiharu OKANO, Nihon University

\begin{abstract}
This report describes of "the control of analysis of unicycle" by using unicycle robot model that the author suggested. The author study with the intention of explaining how human can ride a unicycle well. So in this study, we took notice of motions. They are pedaling and steering. Then author made a unicycle robot by using fuzzy control theory. The author researched whether the method is valid for controlling the unicycle robot.
\end{abstract}

Key Words: < unicycle robot, fuzzy control theory >

\section{1. 序論}

この研究は，人間の一輪車操縦アルゴリズムに興味を持ち， そ扟を解き明かすことを目的としているが，その過程のひと つとして，人間の動作を模した自立ロボットを製作したもの である。一輪車の操縦は前後方问の制御 (pitch) と横方问 の制御（roll）とからなり，前後方向については駆動力で， 横方问については，腰をひ权ることによる操舵によって行っ ていると考えられる。前後方向と横方向とが連成しているこ とが特微である，この動作を模した自立ロボットに 3 次元 FuZZyルールを適用した結畏を跟告する。

2. 1 制御方法

$$
2 \text { ：理谕 }
$$

我从が学案した制御方法は，次の通りである。Pitch 制御

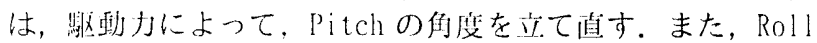
制御は，愳をひ权る動作，操舵をすることによって，嗃心力

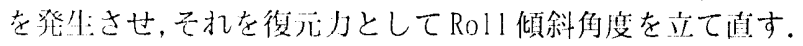

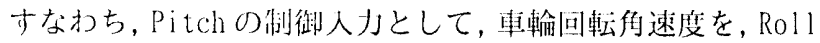
制㓩に操舵觕速度を使朋する。

\section{2 一輸直モデル}

上で述べた制御方法をふまえて一䡒車ロボットモデルを 考案した。一輪車ロボットモデルをFig 2-1に亦す.また, 設定した主要なバラメータをTable 2-1に示す。

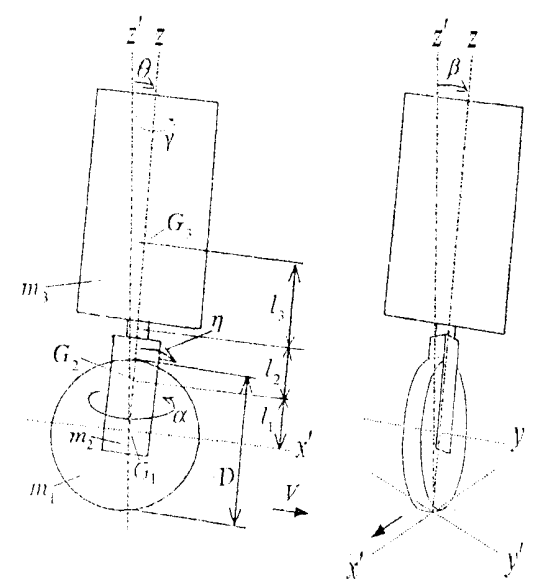

Fig 2-1 The Unicycle Robot Model

\begin{tabular}{|c|c|}
\hline \multicolumn{2}{|c|}{ Table $2-1$} \\
\hline$=$ & 意味 \\
\hline$\alpha$ & 操舵角 \\
\hline $\bar{\beta}$ & 横傾斜俑 \\
\hline $\bar{\theta}$ & 前後傾斜角 \\
\hline$\eta$ & 車輪回転何度 \\
\hline
\end{tabular}

また, Pitch, Rollへの制御人力值は, それぞれ, $\theta ， \dot{\theta}$ ， $\eta$ の 3 つ $\beta, \dot{\beta}, \dot{\eta}$ のつの值により決定する 3 次元ファ ジィルールとした。方により表を分け，車輪回転角速度を決 定するものをTable $2-2 \sim 4$ に，擐舵侜速度を決定するも のをTable 2-5〜 7 に示す.

Table $2-2$ Pitch Control Fuzzy Rule 1

\begin{tabular}{c|c|c|c|c|}
\multirow{2}{*}{$\pi=P$} & \multicolumn{4}{|c|}{$\theta$} \\
\cline { 2 - 5 }$\pi$ & $P$ & $Z \mathrm{O}$ & $N$ \\
\hline \multirow{2}{*}{$\dot{\theta}$} & $P$ & 0.6 & 0.2 & -0.2 \\
\cline { 2 - 5 } & $Z \mathrm{O}$ & 0.2 & -0.2 & -0.6 \\
\cline { 2 - 5 } & $\mathrm{N}$ & -0.2 & -0.6 & -1 \\
\hline
\end{tabular}

\begin{tabular}{c|c|c|c|c|}
\multirow{2}{*}{$n=Z O$} & \multicolumn{3}{|c|}{$\theta$} \\
\cline { 2 - 5 }$n$ & $P$ & $Z O$ & $N$ \\
\hline \multirow{2}{*}{$\dot{\theta}$} & $P$ & 0.8 & 0.4 & 0 \\
\cline { 2 - 5 } & $2 \mathrm{~N}$ & 0.4 & 0 & -0.4 \\
\cline { 2 - 5 } & 0 & -0.4 & 0.8 \\
\hline
\end{tabular}

\begin{tabular}{c|c|c|c|c|}
\multirow{2}{*}{$n$} & \multicolumn{3}{|c|}{$\theta$} \\
\cline { 2 - 5 }$n$ & $P$ & $z Q$ & $N$ \\
\hline \multirow{2}{*}{$\theta$} & $P$ & 1 & 0.6 & 0.2 \\
\cline { 2 - 5 } & $Z \mathrm{O}$ & 0.6 & 0.2 & -0.2 \\
\cline { 2 - 5 } & $N$ & 0.2 & -0.2 & -0.6 \\
\hline
\end{tabular}

Table $2-5$ Roll Control Fuzzy Rulc 1

\begin{tabular}{c|c|c|c|c|}
\multicolumn{2}{c|}{$\pi=\mathrm{F}$} & \multicolumn{3}{|c|}{$\beta$} \\
\cline { 2 - 5 }$\pi$ & $\mathrm{P}$ & $Z \mathrm{O}$ & $N$ \\
\hline \multirow{2}{*}{$\dot{3}$} & $\mathrm{~F}$ & 0.5 & 0.25 & 0 \\
\cline { 2 - 5 } & $\mathrm{ZO}$ & 0.25 & 0 & -0.25 \\
\cline { 2 - 5 } & $\mathrm{N}$ & 0 & -0.25 & -0.5 \\
\hline
\end{tabular}


Table $2-6$ Roll Control Fuzzy Rule 2

\begin{tabular}{c|c|c|c|c|}
\multirow{2}{*}{$\pi$} & \multicolumn{3}{|c|}{$\beta$} \\
\cline { 2 - 5 }$\pi$ & $P$ & $Z O$ & $N$ \\
\hline \multirow{2}{*}{$B$} & $P$ & 0.75 & 0.5 & 0 \\
\cline { 2 - 5 } & $z O$ & 0.5 & 0 & -0.5 \\
\cline { 2 - 5 } & $N$ & 0 & -0.5 & -0.75 \\
\hline
\end{tabular}

\begin{tabular}{c|c|c|c|c|}
\multicolumn{2}{c|}{$\pi$} & \multicolumn{3}{|c|}{$\beta$} \\
\cline { 2 - 5 } & $P$ & $Z O$ & $N$ \\
\hline \multirow{3}{*}{$B$} & $P$ & 1 & 0.75 & 0 \\
\cline { 2 - 5 } & $Z O$ & 0.75 & 0 & -0.75 \\
\cline { 2 - 5 } & $N$ & 0 & -0.75 & -1 \\
\hline
\end{tabular}

二机のフアジルールにより重みを決定し，その值にゲ インを慗ずることによって制御人力を決定する。また，今回 はメンバーシッブ関数に三解形型を使用している。

\section{3.策験装置}

一检糨ロボットの 3 つのジャイロセンサから角速度を検 出し，これを変換することにより角度 $\alpha, \beta, \theta$ を得る。ま た，制御システムはロボットの情報を受け取り，2つのアク チュエータ（舆舵用モータ，駆動用モータ）に制御入力を与 え，各モ一夕に付属のエンコーダーより，実際の回転角度を 得るという構成になっている。 また，発射台の使用により初 剘詣による竞差を最低限度に抑えている。

\section{4. 結果}

Fig 4-1，2，3に実験によって得られたデータの一つ

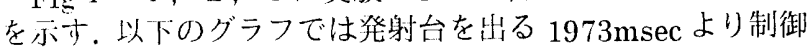
を開始している。なお，ここで㢦動指示電压は $\eta$ と，操舵指

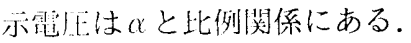

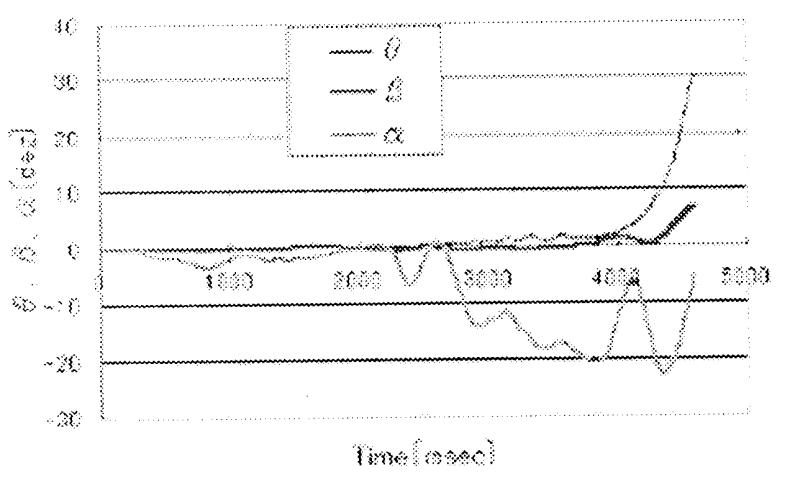

F i g 4-1 Running Data

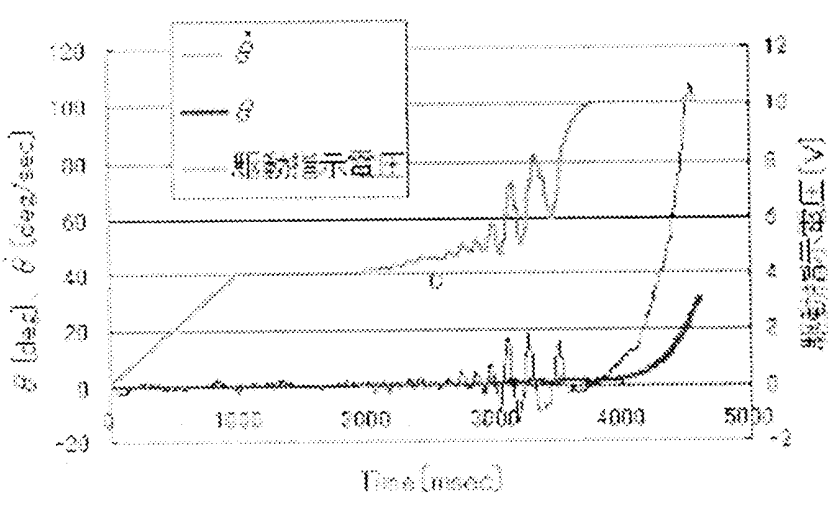

F i g 4-2 Pitch Control

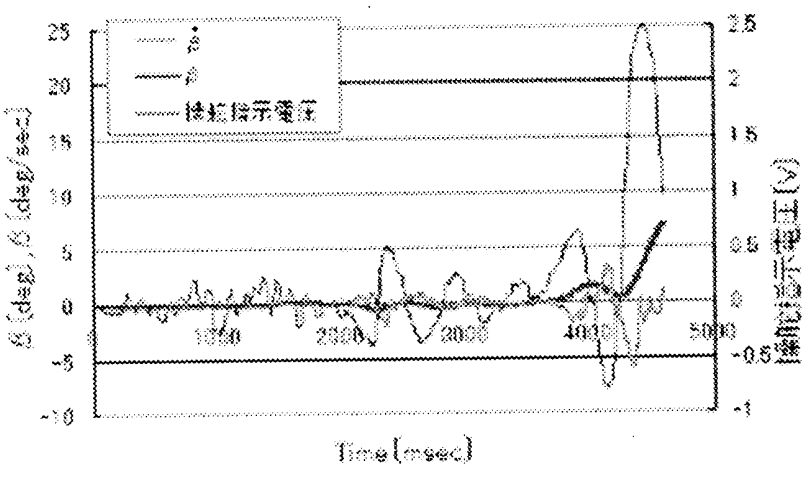

F i g 4-3 Roll Control

5. 考察

操舵

まず，操舵に関していえば，Fig 4-3の 2000msec から $3500 \mathrm{msec}$ の間に $\beta, \dot{\beta}$ ともに振幅が減少し, 操舵指示電圧 も減少していく事から，ここで提案した 3 次元のファジィル 一ルが有效である事がわかる。一旦収束に向かった横方向の 制御が 4000msec 付近で乱れているのは前に倒れていったこ とによる影響である。

\section{- 駆動}

Fig 4-1より，ここでは前に倒れていることがわかる. $4-2$ で, $\theta, \dot{\theta}$ と, 駆動指示電圧の振幅が大きくなってい っていることからも pitch 制御に問題があるということが分 かる。振幅が大きくなる原因は $\eta$ 上昇にともない，市の上昇 を抑制しようとするために制御力が不足するためである。こ こで，駆動指示電圧が振幅を大きくしながら，徐々に上昇し て，最大值に達してしまう事により，それ以上加速できなく なることが一輪車ロボットの倒れる直接の原因となってい る.

\section{- 問題点}

pitchには車輪回転角加速度を与えることで制御している。 このため，前に傾いたらその分だけ速度が上昇した点に釣り 合いの中心が移動することになる。これを繰り返すことで， モータの限界速度に達してしまう。これを緩和するために， 高速度では減速気味に, 低速度では加速気味のルールにして みたが，中速度を離れるほど, 制御力が不足することになっ た。仮にモ一夕の限界速度が上がったとしても，限界速度に 達しないように速度を抑制する必要があることに変わりは ない.

6 . 結 論

1.Roll 制御にはここで提案した 3 次元ファジィルールが有 効である。

2. Pitch 制御は, 今回のルールでは制御力が不足すること がわかった。

7. 参考文献

ファジィ制御管野道夫 著 日刊工業新聞社

アドバンストフアジィ制御田中一男著 共立出版 インテリジェント制御システム 田中一男 著 共立出版 